\title{
"Annales historiques de la Révolution française" 395, janvier-mars 2019, dossier Des Antilles aux Indes orientales
}

\section{Carminella Biondi}

\section{(2) OpenEdition Journals}

Édition électronique

URL : https://journals.openedition.org/studifrancesi/31748

DOI : 10.4000/studifrancesi.31748

ISSN : 2421-5856

Éditeur

Rosenberg \& Sellier

\section{Édition imprimée}

Date de publication : 1 août 2020

Pagination : 403-404

ISSN : 0039-2944

\section{Référence électronique}

Carminella Biondi, «"Annales historiques de la Révolution française" 395, janvier-mars 2019, dossier Des Antilles aux Indes orientales ", Studi Francesi [En ligne], 191 (LXIV | II) | 2020, mis en ligne le 01 septembre 2020, consulté le 18 septembre 2021. URL : http://journals.openedition.org/studifrancesi/ 31748 ; DOI : https://doi.org/10.4000/studifrancesi.31748

Ce document a été généré automatiquement le 18 septembre 2021.

\section{cc) $($ ) $\ominus$}

Studi Francesi è distribuita con Licenza Creative Commons Attribuzione - Non commerciale - Non opere derivate 4.0 Internazionale. 


\title{
"Annales historiques de la Révolution française" 395, janvier- mars 2019, dossier Des Antilles aux Indes orientales
}

\author{
Carminella Biondi
}

\section{RÉFÉRENCE}

"Annales historiques de la Révolution française" 395, janvier-mars 2019, dossier Des Antilles aux Indes orientales, la Révolution française et la question coloniale, pp. 29-235.

1 L'intérêt de ce numéro réside dans le choix de faire un tour d'horizon global du problème colonial à l'époque révolutionnaire et postrévolutionnaire, sans se limiter, comme il arrive le plus souvent pour des raisons objectives, à son côté atlantique. Un choix qui amène à des résultats importants et parfois inattendus, permettant de reconsidérer l'un des phénomènes les plus connus et les plus discutés de la question coloniale, à savoir le «commerce triangulaire» (Europe, Afrique, Amérique, Europe), que Raphaël MALANGIN propose ici de renommer «commerce quadrangulaire», vu l'implication incontournable des produits venant de l'océan Indien, sans exclure le «bois-d'ébène» (Pièces d'Inde: commerce oriental et domaine atlantique français au XVIII ${ }^{\mathrm{e}}$ siècle, pp. 81-101). Cet article pose la question cruciale du lien entre le commerce oriental et le domaine atlantique de la France: la conclusion à laquelle il arrive, à savoir que «commerce oriental et traite négrière française se sont longtemps épaulés», ouvre de nouvelles voies à la recherche, et a le mérite de placer au centre de l'enquête le domaine colonial oriental qui est resté longtemps marginalisé.

2 Même si cette étude a, à mon avis, un rôle central dans le dossier à cause de son ouverture sur l'ensemble des espaces géographiques convoqués par la question coloniale, toutes les contributions ont le mérite, parfois à partir d'aspects 
apparemment marginaux, de poser les bases ou de faire un bilan des recherches nouvelles. En particulier les recherches d'archives (menées souvent par des étudiants pour leurs mémoires ou leurs thèses) déplacent leur terrain d'enquête du plan de la spéculation abstraite, et parfois répétitive, à celui de l'émergence de faits concrets, qui nous permet de saisir, au jour le jour, les répercussions des évènements révolutionnaires ou postrévolutionnaires sur la vie des personnes et sur l'organisation de leur monde. C'est le cas d'un bon nombre de contributions qui, tout en s'appuyant sur les apports les plus récents de la critique, élargissent le domaine de la recherche aux données inédites des fouilles d'archive: Cécilia ELIMORT-TRANI, Ettre prêtre sous le Consulat et l'Empire en Martinique (pp. 37-56); Bruno MAILLARD, La geôle de Saint-Denis: utopie carcérale et lobby esclavagiste à La Réunion sous le premier empire (pp. 57-79); Erick NoËL, Les gens de couleur de l'océan Indien en France à la veille de la Révolution (pp. 103-116); Michel covo, Le massacre de Fructidor, an IV à Saint-Domingue: violence et politique de race sous le Directoire (pp. 143-169); Éric SAUNIER, «Les lettres de Saint-Marc»: un témoignage de la révolution de Saint-Domingue et de la construction des mentalités dans les ports de traite (pp. 193-206); Vincent COUSSEAU, «Apperçu [sic] succinct sur les derniers évènements de St. Domingue» (1805), par le médecin Jean Decout (pp. 207-218). Les titres nous indiquent que le domaine atlantique reste prioritaire - même si l'océan Indien est présent - mais que la focalisation s'oriente sur des sujets moins fréquentés et apparemment marginaux, comme le rôle de l'église et des prêtres dans le domaine colonial, la situation carcérale ou les répercussions immédiates des événements révolutionnaires sur la situation des ports et des comptoirs de commerce, ou encore sur des épisodes presque inconnus, ou sous-estimés, qui témoignent, si besoin en était, de la complexité de la situation sur place où les alliances pouvaient se faire ou se défaire au gré du chef du moment ou sous la pression d'un danger à éviter. Toutes pièces importantes d'une mosaïque de plus en plus détaillée.

3 L'autre caractéristique à souligner dans les articles cités ci-dessus est leur orientation à privilégier la période qui se situe entre la fin de la Révolution et l'Empire, se faisant ainsi l'écho d'un profond revirement d'attitude face aux colonies, à la traite et à l'esclavage des Noirs. Le texte le plus intéressant sous cet aspect est celui de Pierre SERNA, Tenir les Noirs à l'œil. Hypothèse pour une «iconoirlogie» (pp.171-191), qui, fusionnant les résultats de ses recherches sur la race et sur l'iconologie et les cultures visuelles à partir $d u x$ IIII $^{\mathrm{e}}$ siècle, propose cette nouvelle discipline, dénommée «iconoirlogie», qui essaie de détecter, à partir des images du Noir diffusées en France, «le racialisme tel qu'il apparaît dans le moment postrévolutionnaire, 1799-1830, période de retour à l'ordre [...] d'une société bouleversée au sortir de la Révolution» (p. 171). Dans cette mise en ordre on doit aussi remettre à leur place les Noirs, devenus citoyens français grâce à l'abolition de l'esclavage, en 1794, par la Convention, mais inacceptables en tant qu'égaux par une société qui ne rêve, en majorité, que d'un retour à l'Ancien Régime et donc au rétablissement de l'esclavage. Ce que fait Napoléon en 1802, la même année où paraît le plus révoltant des écrits contre les Noirs et leurs défenseurs, ces Égarements du nigrophilisme de Baudry-Deslozières (ou Des Lozières), colon de Saint-Domingue, qui compare les Noirs à des créatures hybrides entre l'homme et le singe, et n'hésite pas à montrer toute son horreur face à la plus petite contamination de la race blanche, menacée par la seule présence sur le sol français de quelques Africains, qu'il propose de reléguer dans une colonie isolée à Madagascar. Pierre Serna consacre, à juste titre, beaucoup de pages à l'analyse de ce texte paradoxal, 
qui photographie, peut-être avec quelques excès, le revirement d'opinion en France au début $d u \mathrm{XIX}^{\mathrm{e}}$ siècle, confirmé par la publication, l'année précédente, d'un ouvrage «scientifique» à succès: l'Histoire naturelle du genre humain (1801, rééditée en 1824) du médecin Julien-Joseph Virey, qui classe les êtres vivants selon une ligne descendante qui va du profil grec à celui de l'orang-outan, immédiatement précédé par celui du Noir. L'histoire douloureuse de la jeune protagoniste africaine du roman Ourika (1823) de Mme de Duras, également analysée par Pierre Serna en conclusion de son essai, vient confirmer la «tyrannie de l'œil» (p. 191), la puissance du regard marginalisant d'une société qui a fait de cette jeune fille, amenée encore enfant de l'Afrique, une parfaite française par son éducation, mais qui n'ayant pas pu changer la couleur de sa peau l'a reléguée dans les limbes. L'article de Frédéric RÉGENT Des sociétés d'habitation aux révolutions dynamiques sociales, démographiques, juridiques et politiques des populations dans le domaine colonial français (1602-1848), pp. 219-225, conclut le dossier; il embrasse toute la période esclavagiste, dresse un bilan de ses propres recherches mais aussi de l'état des recherches sur la question des rapports entre la France, et en particulier la France révolutionnaire, et ses colonies. Par devoir d'exhaustivité il faut aussi mentionner l'essai de Frédéric SPILLEMAEKER (Guerres révolutionnaires, conspirations et naissance de l'indépendantisme sud-américain. Menaces sur la souveraineté hispanique en Nouvelle-Grenade, au Venezuela et dans l'île de Trinidad. 1791-1806, p.119-141) qui ne concerne pas directement la France et ses colonies à l'époque révolutionnaire et postrévolutionnaire, mais qui étudie l'écho des évènements français dans des domaines coloniaux hispaniques situés dans cet espace esclavagiste des Caraïbes, bouleversé et transformé par la Révolution française.

4 Je voudrais conclure par l'incipit de l'introduction de Bernard GAINOT et Éric SAUNIER (p. 29-35) qui rend hommage à un maître de la recherche dans le domaine historique étudié dans ce numéro: «Voilà un peu plus de trente ans, Yves Benot faisait paraître $L a$ Révolution française et la fin des colonies, 1789-1794 [1988]. Dans le deuxième chapitre, il s'interrogeait sur les raisons du silence des historiens, et singulièrement des historiens de la Révolution française, sur la question coloniale» (p. 29). Ce silence a été brisé au cours de ces dernières années grâce aussi à son magistère et à celui de Michel Vovelle, récemment disparu, qui reçoit en ouverture l'hommage d'amis, d'élèves et d'historiens (pp. 3-27). 